\title{
Effects of Dietary Organic and Inorganic Sulfur on Laying Performance, Egg Quality, Ileal Morphology, and Antioxidant Capacity in Laying Hens
}

\author{
Yoo-Bhin Kim ${ }^{1}$, Sang-Hyeok Lee ${ }^{1}$, Da-Hye Kim $^{1}{ }^{1}$, Hyun-Gwan Lee ${ }^{1}$, Yongjun Choi ${ }^{1} \mathbb{D}$, Sung-Dae Lee ${ }^{2} \mathbb{D}$ \\ and Kyung-Woo Lee ${ }^{1, * \mathbb{D}}$ \\ 1 Department of Animal Science and Technology, Konkuk University, Gwangjin-gu, Seoul 05029, Korea; \\ ybin51@naver.com (Y.-B.K.); the_shinism@naver.com (S.-H.L.); kdh142536@naver.com (D.-H.K.); \\ leehyun3177@naver.com (H.-G.L.); cyj2114@gmail.com (Y.C.) \\ 2 National Institute of Animal Science, Rural Development of Administration (NIAS-RDA), \\ Wanju 55365, Korea; leesd@korea.kr \\ * Correspondence: kyungwoolee@konkuk.ac.kr; Tel.: +82-2-450-0495
}

check for updates

Citation: Kim, Y.-B.; Lee, S.-H.; Kim, D.-H.; Lee, H.-G.; Choi, Y.; Lee, S.-D.; Lee, K.-W. Effects of Dietary Organic and Inorganic Sulfur on Laying Performance, Egg Quality, Ileal Morphology, and Antioxidant Capacity in Laying Hens. Animals 2022, 12, 87. https://doi.org/ 10.3390/ani12010087

Academic Editor:

Sylwester Świątkiewicz

Received: 8 December 2021

Accepted: 29 December 2021

Published: 31 December 2021

Publisher's Note: MDPI stays neutral with regard to jurisdictional claims in published maps and institutional affiliations.

Copyright: (C) 2021 by the authors. Licensee MDPI, Basel, Switzerland. This article is an open access article distributed under the terms and conditions of the Creative Commons Attribution (CC BY) license (https:// creativecommons.org/licenses/by/ $4.0 /)$.
Simple Summary: Oxidative stress caused by environmental and nutritional factors could be detrimental to poultry production. Dietary natural antioxidants could therefore be beneficial in limiting the deleterious effects of oxidative stress in chickens. Methyl sulfonyl methane is a non-toxic natural organosulfur compound with the chemical formula $\left(\mathrm{CH}_{3}\right)_{2} \mathrm{SO}_{2}$ and is known as methyl sulfone or dimethyl sulfone. Inorganic sulfate (e.g., sodium sulfate) is involved in the metabolism of many tissues and systems, as well as in important detoxication mechanisms. Dietary sulfur in either organic or inorganic forms exhibits beneficial antioxidant properties in various animals in vivo and in vitro. Therefore, our studies have been conducted to evaluate the role of organic and inorganic sulfur in laying hens.

Abstract: The present study was conducted to investigate the comparative effects of organic and inorganic forms of sulfur, methyl sulfonyl methane (MSM) and sodium sulfate (SS), on laying performance, egg quality, ileal morphology, ileal volatile fatty acids, and antioxidant and stress markers in various biological samples in aged laying hens. A total of 144, 73-week-old Lohman Brown-Lite laying hens were randomly assigned to one of three experimental diets: basal diet $(\mathrm{CONT}), \mathrm{CONT}+0.2 \% \mathrm{MSM}(\mathrm{MSM})$, and CONT $+0.3 \% \mathrm{SS}$ (SS). The trial lasted for 12 weeks. MSM and SS diets contained $0.07 \%$ of sulfur, either organic or inorganic. Dietary MSM did not affect egg production or feed conversion ratio at 12 weeks compared with the CONT group. Dietary sulfur did not affect egg quality except for the Haugh unit at 4 weeks, which was lowered $(p<0.05)$ in the SS group. Compared with the CONT group, a higher $(p<0.05)$ villus height to crypt depth ratio was observed in the SS group. Dietary sulfur did not affect the percentages of short-chain fatty acids in the ileum. Total antioxidant capacity of the liver increased $(p<0.05)$ in laying hens fed MSMand SS-added diets compared with the CONT group. The MSM and SS groups were found to have lowered $(p<0.05)$ malondialdehyde (MDA) concentration in serum samples compared with CONT. Finally, dietary MSM had the lowest $(p<0.05)$ MDA concentrations in yolk samples. Taken together, our study showed that dietary organic and inorganic sulfur have positive effects on ileal morphology and antioxidant capacity in laying hens. However, SS-mediated inhibition in laying performance needs to be clarified.

Keywords: methyl sulfonyl methane; sodium sulfate; laying hen; antioxidant capacity

\section{Introduction}

Oxidative stress defines a disturbed balance between production of free radicals and their elimination by the antioxidant defense systems [1]. It has been well acknowledged that 
oxidative stress caused by environmental and nutritional factors could cause production loss in poultry [2]. Thus, dietary supplementation of natural or synthetic antioxidants in the diets of chickens has been a nutritional strategy to reduce oxidative damage [3]. There are demands for using natural products that can prevent lipid oxidation in fat-enriched animal foods due to consumer preferences for natural substances and toxicological concerns about synthetic antioxidants [4]. The natural antioxidant can fully replace the synthetic antioxidant function and be used as a valuable source for reducing oxidative stress [5,6]. Thus, dietary natural antioxidants could be beneficial in limiting the deleterious effects of oxidative stress in chickens $[7,8]$.

Methyl sulfonyl methane (MSM), also known as $\mathrm{DMSO}_{2}$, or organic sulfur, is an antioxidant agent [9] and is naturally occurring in plants and animals. Dietary MSM has been used to improve antioxidant capacity and to reduce inflammation, joint/muscle pain, and oxidative stress in humans $[10,11]$. It has been reported that MSM, as a sulfur supplement, is nontoxic upon consumption, and is a safer source of sulfur compared with sulfur-containing amino acids (methionine and cyst(e)in), which are toxic at a high intake [12]. In addition to its antioxidant capacity, MSM has been reported to possess various biological activities, being associated with antimicrobials and immune modulations in mice [13], ducks [14], and laying hens [15].

Sodium sulfate anhydrous (SS), inorganic sulfur, is used as a viscosity-increasing agent in cosmetic formulations [16]. As sulfate is involved in various metabolic and detoxication processes, it seems reasonable to add an adequate level of sulfur in the diet [17]. Reid and Weber [18] reported that the requirement of sulfur-containing amino acids in chickens could be partially met by dietary supplementation of inorganic sulfate, indicating the possibility of replacing the pools of methionine or cysteine. Wong et al. [12] suggested that inorganic sulfate could also be used for sulfation of acetaminophen to reduce toxicity and for sulfation of mucin secreted by the intestine, which is incorporated into various tissues. In addition, dietary inorganic sulfur has been known to possess various biological activities, including antioxidant, anti-inflammatory, and antibiotic activities in pigs [19] and broilers [20].

It is thus clear that dietary sulfur in either organic or inorganic forms exhibits beneficial antioxidant properties in various animals in vivo and in vitro [21,22]. However, the antioxidant role of sulfur [23] may not be attributable to its structure due to the lack of direct quenching oxidant activity and of functional groups (e.g., hydroxy groups) [24]. In addition, no studies have been conducted to evaluate the role of organic and inorganic sulfur in laying hens. Therefore, we attempted to investigate the effects of MSM and SS, as sources of organic and inorganic sulfur, on laying performance, egg quality, and antioxidant capacity in laying hens. As sulfur exhibits antimicrobial properties [25], gut health and stress indicators, including ileal morphology and ileal short-chain fatty acids (SCFAs) and corticosterone in eggs, were also analyzed. It was anticipated that the information obtained would be useful in assessing the value of adding sulfur to the feed of laying hens and could lead to the construction of hypotheses to be tested in further studies.

\section{Materials and Methods}

\subsection{Test Materials}

Methyl sulfonyl methane (Sigma-Aldrich, St. Louis, MO, USA) is in the form of a white crystalline powder and contains $34.1 \%$ sulfur on a weight basis. MSM contents in the basal and experimental diets were measured using gas chromatography as described by Park and Lee [26].

Sodium sulfate (Samchun Chemicals, Pyeongtaek, Korea) is an inorganic compound with the formula $\mathrm{Na}_{2} \mathrm{SO}_{4}$ and contains $22.6 \%$ sulfur on a weight basis. Both MSM and SS are white solids that are highly soluble in water.

\subsection{Birds and Experimental Design}

A total of 144, 73-week-old laying hens (Lohmann Brown-Lite) were randomly assigned to one of three dietary groups with eight replicates per group. Two hens were raised in a cage 
$(45 \mathrm{~cm} \times 45 \mathrm{~cm} \times 45 \mathrm{~cm})$ in a windowless, fan-ventilated house, and the adjacent three cages were considered as replicates ( $n=6$ birds/replicate). During an experimental period of 12 weeks, laying hens were fed corn and soybean meal-based diets supplemented without (CONT) or with equal amounts of sulfur $(0.7 \mathrm{~g} \mathrm{~S} / \mathrm{kg}$ of diet) from MSM $(2.0 \mathrm{~g} / \mathrm{kg}$ of diet $)$ or SS ( $3.0 \mathrm{~g} / \mathrm{kg}$ of diet). We decided to choose $0.7 \mathrm{~g} \mathrm{~S} / \mathrm{kg}$ of diet based on an earlier study showing that dietary MSM at $0.2 \%(0.7 \mathrm{~g} \mathrm{~S} / \mathrm{kg}$ of diet) improved egg quality and enhanced cell-mediated immune response in laying hens [15]. Sulfur contents in the basal and experimental diets were measured with an elemental analyzer (EA 1110 CHN; CE instruments, Rodano, MI, Italy). The analyzed total sulfur contents of the CONT, MSM, and SS diets were $0.15,0.31$, and $0.30 \%$, respectively. The aged laying hens in this study were chosen as oxidative stress increases with the age of laying hens [27].

As SS contains $32.4 \%$ sodium, when added at $3.0 \mathrm{~g} / \mathrm{kg}$, the SS diet provided an extra $0.97 \mathrm{~g}$ $\mathrm{Na} / \mathrm{kg}$ of diet. Thus, sodium bicarbonate was added in the CONT and MSM diets at $3.5 \mathrm{~g}$ per $\mathrm{kg}$ of diet to provide amounts of sodium equal to the SS diet. MSM, SS, and sodium bicarbonate were first pre-mixed with a carrier before mixing them with the basal diet to formulate the experimental diets. The ingredients and composition of the basal diet are shown in Table 1. All experimental diets were formulated to meet or exceed the nutrient requirements of aged brown egg-laying hens as recommended by the Korean Feeding Standards for Poultry [28]. The MSM contents were analyzed to contain $0.03 \%, 0.17 \%$, and $0.03 \%$ in the CONT, MSM, and SS diets, respectively.

Table 1. Ingredient and nutrient composition of the basal diet.

\begin{tabular}{|c|c|}
\hline Ingredients & $\mathrm{g}$ per $100 \mathrm{~g}$ of Diet \\
\hline Corn & 41.00 \\
\hline Soybean meal, $45 \%$ crude protein & 10.41 \\
\hline Wheat & 12.80 \\
\hline Animal fat & 1.02 \\
\hline Rice bran & 2.00 \\
\hline Corn steep liquor & 1.00 \\
\hline Rapeseed meal & 3.00 \\
\hline Dried distillers grains with solubles & 12.83 \\
\hline Molasses & 2.00 \\
\hline Liquid choline, $50 \%$ & 0.06 \\
\hline Limestone & 10.51 \\
\hline Monodicalcium phosphate & 1.02 \\
\hline $\mathrm{NaCl}$ & 0.24 \\
\hline Variable & 1.59 \\
\hline Methionine, $100 \%$ & 0.07 \\
\hline Lysine, $54 \%$ & 0.10 \\
\hline Tryptophan, $10 \%$ & 0.10 \\
\hline Mineral mix ${ }^{1}$ & 0.14 \\
\hline Vitamin $\operatorname{mix}^{2}$ & 0.12 \\
\hline Total & 100.00 \\
\hline Nutrient composition, $\mathrm{g} / 100 \mathrm{~g}$ & \\
\hline $\begin{array}{l}\text { Nitrogen-corrected apparent metabolizable energy, } \\
\qquad \mathrm{kcal} / \mathrm{kg}\end{array}$ & 2600 \\
\hline Dry matter 3 & 88.20 \\
\hline Crude protein ${ }^{3}$ & 14.49 \\
\hline Crude fat ${ }^{3}$ & 4.01 \\
\hline Crude ash ${ }^{3}$ & 14.84 \\
\hline Calcium ${ }^{4}$ & 4.10 \\
\hline Sulfur ${ }^{3}$ & 0.15 \\
\hline Available phosphorus 4 & 0.28 \\
\hline Total lysine ${ }^{4}$ & 0.65 \\
\hline Total methionine ${ }^{4}$ & 0.32 \\
\hline Total methionine + cysteine ${ }^{4}$ & 0.60 \\
\hline Methyl sulfonyl methane ${ }^{3}$ & 0.03 \\
\hline
\end{tabular}

${ }^{1}$ Mineral mixture provided the following nutrients per $\mathrm{kg}$ of diet: $\left.\mathrm{Fe}\left(\mathrm{FeSO}_{4} \cdot \mathrm{H}_{2} \mathrm{O}\right), 50 \mathrm{mg} ; \mathrm{Cu}_{(\mathrm{CuSO}} \cdot \mathrm{H}_{2} \mathrm{O}\right)$

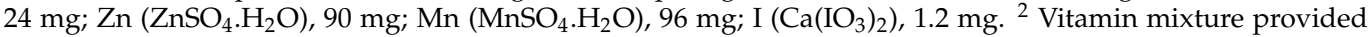
the following nutrients per $\mathrm{kg}$ of diet: vitamin A, 15,400 IU; vitamin D3, $3080 \mathrm{IU}$; vitamin E, $14 \mathrm{mg}$; vitamin K3, $1.4 \mathrm{mg}$; vitamin B1, $1.12 \mathrm{mg}$; vitamin B2, $2.8 \mathrm{mg}$; vitamin B6, $3.92 \mathrm{mg}$; vitamin B12, $0.014 \mathrm{mg}$. ${ }^{3}$ Analyzed value. ${ }^{4}$ Calculated value.

Feed and water were supplied to allow ad libitum consumption during the experimental period. A lighting program of $15 \mathrm{~h}$ of light and $9 \mathrm{~h}$ of dark was applied for the 
entire experimental period. The temperature and relative humidity in the experimental room were maintained at $21 \pm 2{ }^{\circ} \mathrm{C}$ and $60 \%$.

\subsection{Laying Performance and Egg Quality}

Feed consumption per replicate was recorded monthly and used to calculate daily feed intake per bird. Egg production and egg weight were daily recorded and used to calculate the egg mass. The percentage of dirty and broken eggs was calculated as (total number of dirty and broken eggs per replicate/total number of eggs per replicate) $\times 100$. The feed conversion ratio was calculated as feed intake/egg mass per replicate.

On the last three consecutive days at 4, 8, and 12 weeks, six intact eggs per replicate were collected for egg quality assessment. Eggshell color was estimated with a shell color reflectometer (TSS QCR, Technical Services and Supplies, York, UK). Haugh unit, eggshell strength, eggshell thickness (without shell membrane), and yolk color score were assessed with a digital egg tester (DET-6000, Nabel, Kyoto, Japan). Yolk color was automatically graded on a scale of 1-16, with 1 being a very pale yellow and 16 being a dark orange. The separated yolks were weighed after clearing adherent albumin residues with filter paper [29]. Eggshells were cleaned to remove the adherent albumen, dried at room temperature for 3 days, and weighed. Albumen weight was then calculated by subtracting yolk and dry eggshell weights from the initial egg weight.

\subsection{Corticosterone and Malondialdehyde in Egg Yolk}

Three eggs per replicate were collected for the determination of corticosterone in egg yolks at 4,8 , and 12 weeks. The eggs were broken, yolk was separated from albumen, and separated yolks were placed in plastic bags. The pooled yolk per replicate was homogenized and used to measure corticosterone (Enzo Life Sciences, Inc., ADI-901-097, Farmingdale, NY, USA). Pooled yolks were then centrifuged at $1200 \times \mathrm{g}$ for $5 \mathrm{~min}$ at $4{ }^{\circ} \mathrm{C}$. The supernatants were analyzed for malondialdehyde (MDA; Cell Biolabs, Inc., San Diego, CA, USA) per the recommendation by the manufacturers.

\subsection{Ileal Morphology}

At 12 weeks, one hen per replicate was euthanized with an overdose of carbon dioxide. Immediately after euthanasia, the small intestine was excised, and a segment of mid-ileum was sampled. Approximately, a $1 \mathrm{~cm}$-long mid-segment of the ileum was fixed in $10 \%$ neutral buffered formalin for $48 \mathrm{~h}$, dehydrated, and embedded in a paraffin block. Histological sections ( $5 \mu \mathrm{m}$ thick) were stained with hematoxylin and eosin per standard histological technique. The mucosa was examined by a light microscope (Olympus BX43, Tokyo, Japan) and photographed using a digital camera (eXcope T500, DIXI Science, Daejeon, Korea). Ten intact well-oriented villi and crypts were counted for villus height and crypt depth. Villus height was measured from the villus tip to the villus bottom and crypt depth was defined from villus bottom to the crypt. The ratio of villus height and crypt depth was then calculated.

\subsection{Short-Chain Fatty Acids Analysis}

At the end of the experiment (i.e., 12 weeks), approximately $1 \mathrm{~g}$ of ileal digesta was sampled from one bird per replicate and thoroughly homogenized in $4 \mathrm{~mL}$ of cold distilled water using a vortex mixer. The homogenate was then added to $0.05 \mathrm{~mL}$ of saturated $\mathrm{HgCl}_{2}, 1 \mathrm{~mL}$ of $25 \%$ $\mathrm{H}_{3} \mathrm{PO}_{4}$, and $0.2 \mathrm{~mL}$ of $2 \%$ pivalic acid and centrifuged at $1000 \times \mathrm{g}$ at $4{ }^{\circ} \mathrm{C}$ for $20 \mathrm{~min}$. To measure the concentrations of SCFAs by gas chromatography (6890 Series GC System; HP, Palo Alto, CA, USA) as described by Kim et al, $1 \mathrm{~mL}$ of supernatant was used [30].

\subsection{Antioxidant Markers in Liver and Serum Samples}

At 12 weeks, livers were sampled and stored on ice until further preparation on the day of the sampling. Approximately $1 \mathrm{~g}$ of liver was mixed in $9 \mathrm{~mL}$ of cold $1 \mathrm{X}$ PBS and homogenized (Digital Ultra-Turrax T25, IKA, Staufen, Germany). The homogenate was then centrifuged at $10,000 \times g$ for $10 \mathrm{~min}$, and the aliquot of the supernatant was stored at $-20^{\circ} \mathrm{C}$ 
until analysis. The diluted aliquot was used for the determination of glutathione peroxidase (GPX; EnzyChrom GPx, BioAssay Systems, Hayward, CA, USA), total antioxidant capacity (TAC; QuantiChrom Antioxidant, BioAssay Systems, Hayward, CA, USA), catalase (CAT; Cell Biolabs, Inc., San Diego, CA, USA), and MDA (Cell Biolabs, Inc., San Diego, CA, USA) per the instructions described by the manufacturers. The results were normalized against total protein concentration in each sample. Total protein concentration in liver was quantified as described by Bradford [31] using bovine serum albumin.

Approximately $3 \mathrm{~mL}$ of blood per hen (one hen per replicate) was drawn from the wing vein into the clot activator tube at 4,8, and 12 weeks. Serum samples were obtained by gentle centrifugation $(200 \times g)$ for $15 \mathrm{~min}$ and stored at $-20{ }^{\circ} \mathrm{C}$ before analysis. Serum samples were used to measure various biomarkers of oxidative stress, including levels of GPX, superoxide dismutase (SOD), TAC, CAT, MDA, and 8-hydroxydeoxyguanosine (8-OHdG). SOD was analyzed using an SOD determination assay kit-WST (Sigma, St. Louis, MO, USA) and expressed as SOD activity (inhibition rate, \%). As an indicator of oxidative DNA damage, 8-OHdG was determined using an 8-OHdG DNA Damage ELISA Kit (Cell Biolabs, Inc., San Diego, CA, USA) and was presented in ng/mL. All assays were conducted per the recommendations specified by the manufacturers.

\subsection{Statistical Analysis}

All data were analyzed by one-way ANOVA using PROC GLM (v9.4; SAS Institute Inc., Cary, NC, USA). Treatment means were separated using Duncan's multiple range test [32]. The significance level was pre-set at $p<0.05$.

\section{Results}

\subsection{Laying Performance and Egg Quality}

The production performance of laying hens fed diets with different sulfur sources is presented in Table 2. At weeks 4 and 8, feed intake was lowest $(p<0.05)$ in the SS group compared with the CONT and MSM groups. SS vs. MSM significantly lowered $(p<0.05)$ feed intake at 4 weeks. The SS-mediated depression in feed intake was not noted $(p>0.05)$ by the time of 12 weeks. Egg production was lowest $(p<0.05)$ in the SS group compared with the CONT and MSM groups at 8 and 12 weeks. Feed conversion ratio was significantly elevated $(p<0.05)$ in the SS-fed laying hens compared with the CONT and MSM groups at 8 and 12 weeks.

Table 2. Effects of dietary sulfur on production performance in laying hens $(n=8)$.

\begin{tabular}{cccccc}
\hline Item & CONT $^{\mathbf{1}}$ & MSM & SS & SEM $^{2}$ & $p$-Value \\
\hline Feed intake, g/bird & & & & & \\
4 weeks & $107.6^{\mathrm{a}}$ & $101.4^{\mathrm{b}}$ & $98.2^{\mathrm{c}}$ & 0.91 & $<0.001$ \\
8 weeks & $102.0^{\mathrm{a}}$ & $103.9^{\mathrm{a}}$ & $95.7^{\mathrm{b}}$ & 1.75 & 0.011 \\
12 weeks & 107.7 & 108.2 & 109.7 & 2.09 & 0.839 \\
Egg production, \% & & & & & \\
4 weeks & $81.9^{\mathrm{a}}$ & 82.4 & 78.7 & 1.89 & 0.405 \\
8 weeks & $85.3^{\mathrm{a}}$ & $83.4^{\mathrm{a}}$ & $75.9^{\mathrm{b}}$ & 1.44 & 0.001 \\
12 weeks & $81.5^{\mathrm{a}}$ & $83.2^{\mathrm{a}}$ & $72.4^{\mathrm{b}}$ & 1.59 & 0.002 \\
Feed conversion ratio, $\mathrm{kg} / \mathrm{kg}$ & & & & & \\
4 weeks & $2.08^{\mathrm{b}}$ & 1.98 & 2.06 & 0.04 & 0.332 \\
8 weeks & $1.87^{\mathrm{b}}$ & $1.94^{\mathrm{a}, \mathrm{b}}$ & $2.03^{\mathrm{a}}$ & 0.04 & 0.022 \\
12 weeks & $2.08^{\mathrm{b}}$ & $2.01^{\mathrm{b}}$ & $2.39^{\mathrm{a}}$ & 0.05 & 0.001 \\
\hline
\end{tabular}

$\overline{\mathrm{a}, \mathrm{b}, \mathrm{c}}$ Means value without a common superscript within the same row differ $(p<0.05) .{ }^{1}$ CONT, basal diet; MSM basal diet + methyl sulfonyl methane; SS, basal diet + sodium sulfate. ${ }^{2}$ SEM, standard error of the mean.

Neither MSM nor SS significantly affected the percentages of dirty and cracked eggs at any ages ( $p>0.05$; Table 3$)$. SS-fed laying hens laid lighter eggs by on average $4.0 \%$ at 4 weeks $(p<0.05)$ and $3.1 \%$ at 8 weeks $(p>0.05)$ compared with the CONT. No difference in egg weight 
was noted between dietary treatments at 12 weeks. At 8 and 12 weeks, egg mass was lowest $(p<0.05)$ in the SS group compared with the CONT and MSM groups (Table 3$).$

Table 3. Effects of dietary sulfur on dirty and cracked eggs, egg weight, and egg mass in laying hens $(n=8)$.

\begin{tabular}{cccccc}
\hline Item & CONT $^{\mathbf{1}}$ & MSM & SS & SEM $^{2}$ & $p$-Value \\
\hline Dirty and cracked egg, \% & & & & & \\
4 weeks & 2.17 & 2.16 & 2.68 & 0.67 & 0.875 \\
8 weeks & 2.74 & 1.69 & 2.50 & 0.90 & 0.697 \\
12 weeks & 2.14 & 1.96 & 3.40 & 0.85 & 0.559 \\
Egg weight, g/egg & & & & & \\
4 weeks & $63.42^{\mathrm{a}}$ & $62.21^{\mathrm{a}, \mathrm{b}}$ & $60.90^{\mathrm{b}}$ & 0.48 & 0.014 \\
8 weeks & 64.23 & 64.17 & 62.22 & 0.72 & 0.114 \\
12 weeks & 63.82 & 64.70 & 63.41 & 0.73 & 0.575 \\
Egg mass, g/day & & & & & \\
4 weeks & 51.8 & 51.2 & 47.9 & 1.08 & 0.062 \\
8 weeks & $54.8^{\mathrm{a}}$ & $53.5^{\mathrm{a}}$ & $47.2^{\mathrm{b}}$ & 1.01 & $<0.001$ \\
12 weeks & $51.9^{\mathrm{a}}$ & $53.9^{\mathrm{a}}$ & $45.9^{\mathrm{b}}$ & 0.96 & 0.001 \\
\hline
\end{tabular}

a,b Means value without a common superscript within the same row differ $(p<0.05) .{ }^{1}$ CONT, basal diet; MSM, basal diet + methyl sulfonyl methane; SS, basal diet + sodium sulfate. ${ }^{2}$ SEM, standard error of the mean.

To address the question of whether different sulfur sources would affect internal egg qualities, the compositions and qualities of eggs were monitored at 4-week intervals. None of the dietary sulfur treatments affected egg compositions and qualities except for the Haugh unit at 4 weeks (Table 4$)$. The Haugh unit was lower $(p<0.05)$ in the SS group compared with the CONT and MSM groups at 4 weeks.

Table 4. Effects of dietary sulfur on egg composition and egg quality in laying hens $(n=8)$.

\begin{tabular}{|c|c|c|c|c|c|}
\hline Item & $\mathrm{CONT}^{1}$ & MSM & SS & SEM $^{2}$ & $p$-Value \\
\hline \multicolumn{6}{|l|}{4 weeks } \\
\hline Relative yolk weight, \% & 26.14 & 25.60 & 25.62 & 0.28 & 0.339 \\
\hline Relative eggshell weight, \% & 9.91 & 10.07 & 10.15 & 0.11 & 0.338 \\
\hline Relative albumen weight, $\%$ & 63.94 & 64.39 & 64.21 & 0.29 & 0.574 \\
\hline Yolk color & 6.00 & 6.02 & 6.03 & 0.06 & 0.952 \\
\hline Haugh unit & $76.3^{\mathrm{a}}$ & $78.7^{\mathrm{a}}$ & $72.8^{\mathrm{b}}$ & 0.97 & 0.003 \\
\hline Eggshell strength, $\mathrm{kg} / \mathrm{cm}^{2}$ & 4.90 & 4.99 & 4.89 & 0.20 & 0.919 \\
\hline Eggshell thickness, mm & 0.43 & 0.43 & 0.43 & 0.00 & 0.560 \\
\hline $\begin{array}{l}\text { Eggshell color, unit } \\
8 \text { weeks }\end{array}$ & 28.36 & 27.89 & 27.23 & 0.76 & 0.651 \\
\hline Relative yolk weight, \% & 26.67 & 26.07 & 26.32 & 0.26 & 0.311 \\
\hline Relative eggshell weight, \% & 9.94 & 9.96 & 10.15 & 0.12 & 0.515 \\
\hline Relative albumen weight, $\%$ & 63.38 & 63.95 & 63.52 & 0.29 & 0.417 \\
\hline Yolk color & 6.75 & 6.60 & 6.66 & 0.09 & 0.551 \\
\hline Haugh unit & 76.7 & 76.1 & 73.7 & 0.91 & 0.107 \\
\hline Eggshell strength, $\mathrm{kg} / \mathrm{cm}^{2}$ & 4.82 & 4.74 & 4.47 & 0.15 & 0.308 \\
\hline Eggshell thickness, mm & 0.41 & 0.42 & 0.42 & 0.00 & 0.452 \\
\hline $\begin{array}{l}\text { Eggshell color, unit } \\
12 \text { weeks }\end{array}$ & 27.37 & 28.00 & 27.04 & 0.51 & 0.501 \\
\hline Relative yolk weight, \% & 25.88 & 25.43 & 25.72 & 0.29 & 0.572 \\
\hline Relative eggshell weight, $\%$ & 9.96 & 9.90 & 10.15 & 0.09 & 0.265 \\
\hline Relative albumen weight, $\%$ & 64.14 & 64.67 & 63.88 & 0.32 & 0.311 \\
\hline Yolk color & 6.80 & 6.70 & 6.95 & 0.10 & 0.309 \\
\hline Haugh unit & 75.4 & 77.5 & 74.9 & 1.00 & 0.238 \\
\hline Eggshell strength, $\mathrm{kg} / \mathrm{cm}^{2}$ & 4.56 & 4.62 & 4.66 & 0.11 & 0.974 \\
\hline Eggshell thickness, mm & 0.42 & 0.40 & 0.41 & 0.01 & 0.307 \\
\hline Eggshell color, unit & 28.91 & 28.20 & 26.68 & 0.80 & 0.228 \\
\hline
\end{tabular}

a, b Means value without a common superscript within the same row differ $(p<0.05) .{ }^{1}$ CONT, basal diet; MSM, basal diet + methyl sulfonyl methane; SS, basal diet + sodium sulfate. ${ }^{2}$ SEM, standard error of the mean.

\subsection{Corticosterone and MDA in Yolk Samples}

No difference in yolk corticosterone between dietary treatments was noted at 4,8 , and 12 weeks (Table 5). Dietary MSM did not affect $(p>0.05)$ the MDA contents of egg 
yolks at 4 and 8 weeks compared with the CONT. However, at 12 weeks, MSM-fed, not SS-fed, laying hens had the lowest MDA contents $(p<0.05)$ in egg yolks compared with the CONT group.

Table 5. Effects of dietary sulfur on corticosterone and malondialdehyde contents of egg yolks in laying hens $(n=8)$.

\begin{tabular}{cccccc}
\hline Item $^{\mathbf{1}}$ & CONT $^{\mathbf{2}}$ & MSM & SS & SEM $^{\mathbf{3}}$ & $p$-Value \\
\hline $\begin{array}{c}\text { Corticosterone, pg/g } \\
\text { 4 weeks }\end{array}$ & 325.6 & 403.1 & 429.3 & 38.81 & 0.240 \\
8 weeks & 195.1 & 236.7 & 249.2 & 15.67 & 0.088 \\
12 weeks & 325.7 & 325.7 & 330.8 & 30.84 & 0.993 \\
MDA, nmol/g & & & & & \\
4 weeks & 33.11 & 30.83 & 33.68 & 0.83 & 0.064 \\
8 weeks & 30.00 & 28.21 & 30.89 & 0.83 & 0.115 \\
12 weeks & $29.08^{\text {a }}$ & $21.77^{\text {b }}$ & $27.16^{\text {a }}$ & 0.87 & $<0.001$ \\
\hline
\end{tabular}

a, b Means value without a common superscript within the same row differ $(p<0.05) .{ }^{1}$ MDA, malondialdehyde ${ }^{2}$ CONT, basal diet; MSM, basal diet + methyl sulfonyl methane; SS, basal diet + sodium sulfate. ${ }^{3}$ SEM, standard error of the mean.

\subsection{Ileal Morphology and Ileal SCFA Concentration}

Dietary sulfur treatments did not affect ileal villus height and crypt depth (Table 6). However, villus height:crypt depth ratio was elevated by on average 1.3- and 1.7-fold in the MSM and SS groups compared with the CONT. None of the dietary sulfur treatments affected the relative percentages of SCFAs in ileal digesta at 12 weeks (Table 7).

Table 6. Effects of dietary sulfur on ileal morphology in laying hens $(n=8)$.

\begin{tabular}{cccccc}
\hline Item $^{\mathbf{1}}$ & CONT $^{\mathbf{2}}$ & MSM & SS & SEM $^{\mathbf{3}}$ & $p$-Value \\
\hline Villus height, $\mu \mathrm{m}$ & 807.4 & 905.7 & 1059.0 & 96.00 & 0.285 \\
Crypt depth, $\mu \mathrm{m}$ & 146.0 & 128.6 & 116.4 & 8.69 & 0.136 \\
VH:CD ratio & $5.44^{\mathrm{b}}$ & $7.15^{\mathrm{a}, \mathrm{b}}$ & $9.18^{\mathrm{a}}$ & 0.73 & 0.030 \\
\hline
\end{tabular}

a, b Means value without a common superscript within the same row differ $(P<0.05) .{ }^{1} \mathrm{VH}: \mathrm{CD}$ ratio, villus height to crypt depth ratio. ${ }^{2}$ CONT, basal diet; MSM, basal diet + methyl sulfonyl methane; SS, basal diet + sodium sulfate. ${ }^{3}$ SEM, standard error of the mean.

Table 7. Effects of dietary sulfur on the percentages (\%) of ileal short-chain fatty acids in laying hens $(n=8)$.

\begin{tabular}{cccccc}
\hline Item & CONT $^{\mathbf{1}}$ & MSM & SS & SEM $^{\mathbf{2}}$ & $p$-Value \\
\hline Acetate & 55.86 & 62.01 & 59.59 & 3.22 & 0.421 \\
Propionate & 6.61 & 5.70 & 7.17 & 0.61 & 0.290 \\
Isobutyrate & 5.02 & 5.11 & 6.11 & 1.06 & 0.754 \\
Butyrate & 5.97 & 5.05 & 5.55 & 0.75 & 0.695 \\
Isovalerate & 4.01 & 4.22 & 4.23 & 0.45 & 0.931 \\
Valerate & 4.80 & 3.83 & 4.84 & 0.62 & 0.455 \\
Lactate & 17.74 & 14.09 & 12.51 & 2.71 & 0.422 \\
\hline
\end{tabular}

${ }^{1}$ CONT, basal diet; MSM, basal diet + methyl sulfonyl methane; SS, basal diet + sodium sulfate. ${ }^{2}$ SEM, standard error of the mean.

\subsection{Markers for Oxidative Stress in Liver Samples}

None of the dietary sulfur sources affected ( $p>0.05)$ GPX activity, CAT, and MDA levels in liver (Table 8). It was observed that GPX activity ranged from 51.8 to $59.7 \mathrm{U}$ per $\mathrm{mg}$ of protein, CAT from 65.2 to $70.8 \mathrm{U}$ per mg of protein, and MDA from 1.98 to $2.35 \mathrm{nmol}$ per $\mathrm{mg}$ of protein. The TAC levels in liver were significantly elevated in both MSM and SS groups compared with the CONT group at 12 weeks $(p<0.05)$. 
Table 8. Effects of dietary sulfur on oxidative stress markers of liver in laying hens $(n=8)$.

\begin{tabular}{cccccc}
\hline Item $^{\mathbf{1}}$ & CONT $^{\mathbf{2}}$ & MSM & SS & SEM $^{3}$ & $p$-Value \\
\hline GPX activity, U/mg & 51.83 & 54.38 & 59.71 & 2.59 & 0.224 \\
protein & $52.29^{\mathrm{b}}$ & $63.05^{\mathrm{a}}$ & $65.40^{\mathrm{a}}$ & 1.85 & $<0.001$ \\
TAC, nmol/mg protein & 70.82 & 65.22 & 69.93 & 13.58 & 0.965 \\
CAT, U/mg protein & 2.05 & 1.98 & 2.35 & 0.19 & 0.453 \\
MDA, nmol/mg protein & &
\end{tabular}

a, b Means value without a common superscript within the same row differ $(p<0.05) .{ }^{1}$ GPX, glutathione peroxidase; TAC, total antioxidant capacity; CAT, catalase; MDA, malondialdehyde. ${ }^{2}$ CONT, basal diet; MSM, basal diet + methyl sulfonyl methane; SS, basal diet + sodium sulfate. ${ }^{3}$ SEM, standard error of the mean.

\subsection{Markers for Oxidative Stress in Serum Samples}

Dietary sulfur sources did not affect GPX activity, TAC, CAT, or 8-OHdG in serum samples at all ages (Table 9). Although statistically non-significant, MSM-fed chickens had the highest SOD activity $(p>0.05)$ by on average $28.6 \%$ and $21.2 \%$ at 4 and 12 weeks compared with the CONT group. Laying hens fed diets containing SS vs. MSM showed $(p>0.05)$ similar, higher, or slightly lower SOD activities at 4, 8, and 12 weeks. At 12 weeks, both MSM and SS groups had lower $(p<0.05)$ MDA concentrations in serum samples compared with the CONT group.

Table 9. Effects of dietary sulfur on oxidative stress markers of serum in laying hens $(n=8)$.

\begin{tabular}{|c|c|c|c|c|c|}
\hline Item $^{1}$ & $\mathrm{CONT}^{2}$ & MSM & SS & SEM $^{3}$ & $p$-Value \\
\hline \multicolumn{6}{|c|}{ GPX activity, U/L } \\
\hline 4 weeks & 517.5 & 568.6 & 517.6 & 60.47 & 0.831 \\
\hline 8 weeks & 520.3 & 538.3 & 566.3 & 46.85 & 0.824 \\
\hline 12 weeks & 517.0 & 571.9 & 583.4 & 44.31 & 0.574 \\
\hline \multicolumn{6}{|c|}{ SOD activity, \% } \\
\hline 4 weeks & 74.07 & 95.23 & 95.19 & 7.22 & 0.091 \\
\hline 8 weeks & 74.88 & 79.57 & 87.86 & 5.45 & 0.282 \\
\hline 12 weeks & 85.23 & 103.30 & 92.91 & 5.11 & 0.066 \\
\hline \multicolumn{6}{|l|}{$\mathrm{TAC}, \mathrm{mM}$} \\
\hline 4 weeks & 1.30 & 1.54 & 1.52 & 0.13 & 0.423 \\
\hline 8 weeks & 1.16 & 1.29 & 1.21 & 0.07 & 0.416 \\
\hline 12 weeks & 1.57 & 1.59 & 1.60 & 0.08 & 0.961 \\
\hline \multicolumn{6}{|c|}{$\mathrm{CAT}, \mathrm{U} / \mathrm{mL}$} \\
\hline 4 weeks & 3.06 & 2.59 & 3.19 & 0.36 & 0.541 \\
\hline 8 weeks & 2.60 & 2.43 & 2.78 & 0.42 & 0.851 \\
\hline 12 weeks & 2.45 & 2.96 & 2.63 & 0.23 & 0.341 \\
\hline \multicolumn{6}{|l|}{$\mathrm{MDA}, \mu \mathrm{M}$} \\
\hline 4 weeks & 23.66 & 17.23 & 17.17 & 3.15 & 0.315 \\
\hline 8 weeks & 24.62 & 25.40 & 19.70 & 1.60 & 0.083 \\
\hline 12 weeks & $30.90^{a}$ & $20.65^{b}$ & $20.85^{b}$ & 2.29 & 0.025 \\
\hline \multicolumn{6}{|c|}{ 8-OHdG, ng/mL } \\
\hline 4 weeks & 1.63 & 1.54 & 1.69 & 0.24 & 0.925 \\
\hline 8 weeks & 2.92 & 3.01 & 4.71 & 0.44 & 0.218 \\
\hline 12 weeks & 2.55 & 2.26 & 2.59 & 0.79 & 0.972 \\
\hline
\end{tabular}

a, b Means value without a common superscript within the same row differ $(p<0.05) .{ }^{1}$ GPX, glutathione peroxidase; SOD, superoxide dismutase; TAC, total antioxidant capacity; CAT, catalase; MDA, malondialdehyde; 8-OHdG, 8-hydroxydeoxyguanosine. ${ }^{2}$ CONT, basal diet; MSM, basal diet + methyl sulfonyl methane; SS, basal diet + sodium sulfate. ${ }^{3}$ SEM, standard error of the mean.

\section{Discussion}

Our study showed that laying hens fed diets containing inorganic vs. organic sulfur performed less well, as manifested by the deterioration in feed intake, egg production, feed conversion ratio, egg weight, and egg mass. This finding was unexpected in the light of earlier studies in which impaired laying performance due to SS was only noted at the higher added concentrations of $10,000 \mathrm{ppm}$ in the diet [33] or 16,000 ppm in drinking water [34]. It 
was also reported that dietary sulfate at $1.0 \%$ did not affect egg production and feed intake in laying hens [35]. Furthermore, SS is considered a less toxic sulfur source compared with magnesium sulfate in laying hens [34]. Finally, Ross et al. [36] showed that the addition of SS in a broiler diet at the level of $0.3 \%$ increased body weight gain compared with the no-added diet-fed control. In this sense, the negative effect of dietary SS that emerged from our study is not to be explained in terms of the SS level having been toxic for laying hens. In addition, SS is used in cosmetic formulations as a viscosity-increasing agent and listed as generally recognized as safe (GRAS) by the Food and Drug Administration [37].

Alternatively, the SS-depressed laying performance might be related to differences in sodium sources, although all treatment groups received equal amounts $(1.9 \mathrm{~g} \mathrm{Na} / \mathrm{kg}$ of diet). The control group received sodium from sodium bicarbonate plus $\mathrm{NaCl}$ while the SS group received it from $\mathrm{NaCl}$ plus SS. Indeed, Ahmad et al. [38] reported that dietary SS vs. sodium bicarbonate inhibited water intake in heat-stressed broiler chickens. Thus, it needs to be addressed whether the SS-mediated inhibition of feed intake could be linked to altered water intake or dynamics. In contrast to SS, dietary MSM did not affect laying performance albeit that both SS and MSM were given equal amounts of sulfur. The lack of effect of dietary MSM on performance was reported with laying hens [15] and broiler chickens [11,39].

None of the dietary sulfur sources affected egg quality except for the Haugh unit. Of note, the Haugh unit, an indicator of internal egg quality, was low in SS-fed groups at 4 and 8 weeks. In contrast to our finding, Adams et al. [34] found that SS in drinking water up to 16,000 ppm did not affect the Haugh unit and eggshell thickness in laying hens. A clear explanation is not readily available as to the SS-mediated decrease in the Haugh unit. As the experimental diets contained equal amounts of sulfur, diet-origin sulfur per se in eggs might not be the factor affecting the Haugh unit. Thus, whether an SS-induced decrease in the Haugh unit is related to its impact on albumen components (i.e., ovomucin or lysozyme contents in thick albumen) needs to be addressed.

Corticosterone, a well-known stress hormone in poultry, plays an important role in suppressing immune responses and animal performance [40]. Corticosterone is accumulated in eggs in a chronic manner before ovulation [41]. The concentration of corticosterone detected in this study was within the physiological range, being from 12.82 to $1033 \mathrm{pg}$ in egg yolks [42], indicating a negligible effect of sulfur on stress response in laying hens.

The structure and functionality of the intestinal microbiota are crucial for the health of poultry. Due to the antimicrobial activities of MSM [43] and SS [44], it is expected that their supplementation in the diets of laying hens could balance gut microbiota and improve gut health, which prompted us to measure ileal morphology and ileal SCFAs. Both MSM and SS did not affect ileal SCFAs, but increased villus height and crypt depth ratio, the indicator of gut function and health $[45,46]$. We found that SS vs. MSM was more effective in increasing villus height and crypt depth ratio. Our study is in line with earlier findings [20] showing that duodenal villus height and crypt depth ratio was increased in broilers fed diets to which 2 or $3 \mathrm{~g} \mathrm{~S} / \mathrm{kg}$ of feed were added. Scott et al. [44] indicated that dietary SS was an effective antimicrobial intervention to reduce Salmonella contamination. However, the contradictory finding that SS-induced improvement in gut morphology led to a negative effect on laying performance precludes a conclusion of the positive effect of dietary SS in laying hens. In future, the sulfur-mediated effect on intestinal physiology and health warrants further studies addressing the role of organic vs. inorganic sulfur on gut microbiomes and gut barrier integrity.

Due to the role of sulfur-containing substances as regulators in oxidative stress [23,47], it is expected that both MSM and SS could possess antioxidative properties. Thus, we attempted to measure enzymatic and non-enzymatic antioxidative systems in various biological samples, including eggs, liver, and serum samples. We found that dietary MSM vs. SS was more effective in reducing yolk MDA concentrations. Both MSM and SS raised TAC and SOD activity but lowered MDA in serum samples compared with the CONT. Tentatively, our findings indicate that both MSM and SS have potential as antioxidant feed 
additives in laying hens, although the analyzed antioxidant and oxidative stress parameters were not closely associated.

MDA is a major oxidation product of peroxidized polyunsaturated fatty acids and an important indicator of lipid peroxidation [48]. Dietary MSM has been known to show a wide spectrum of antioxidant activity in humans [49], pigs [50], Pekin ducks [14], and broiler chickens [51,52]. In this sense, our observation that dietary SS decreased MDA concentrations in serum samples might suggest the quenching activity of diet-origin sulfur per se in oxidative stress. However, it seems that there would be other factors in addition to sulfur itself affecting the antioxidative/oxidative balance as yolk MDA concentration was only affected by MSM but not SS. TAC is used to assess the antioxidant status of the body, reflecting all the antioxidant substances present in biological samples [53]. We noted that the concentrations of TAC in liver samples, but not in serum samples, were elevated in laying hens fed diets containing dietary sulfur (both MSM and SS). It has been reported that dietary MSM increased plasma/serum concentrations of TAC in human subjects [49] and Pekin ducklings [14]. However, it should be pointed out that a sulfur-induced increase in TAC concentration was not associated with a concomitant decrease in MDA concentration in liver samples. It is not surprising to see the inconsistent results for dietary antioxidants, including MSM, with oxidant-antioxidant defense biomarkers [52].

SOD is a powerful antioxidant in the cell and an important endogenous antioxidant enzyme acting to suppress or prevent the formation of free radicals [54]. Earlier studies also showed that dietary MSM at the level of $0.3 \%$ increased SOD activity in serum samples of ducks $[14,55]$. However, dietary MSM did not affect SOD activity although it increased the activity by $21.2 \%$ at 12 weeks compared with the CONT group. In contrast to previous studies reporting the beneficial effect of dietary MSM on GPX in broilers, ducklings, and horses $[14,52,56]$, we did not observe an effect of dietary MSM or SS on GPX activity in serum and liver. However, as far as we know, this is the first report to compare the effect of dietary sulfur originated from either organic or inorganic sources on antioxidant capacities in laying hens.

\section{Conclusions}

In conclusion, dietary SS impaired laying performance (i.e., there was a reduction in feed intake and egg production), but improved ileal morphology (i.e., villus height:crypt depth ratio). Both SS and MSM exhibited antioxidative activity. Collectively, our study suggests that dietary sulfur can be used as a potential feed additive to mitigate oxidative stress and to improve the gut health of laying hens, which seems to be beneficial for poultry. Future studies are required to investigate how SS might have inhibited feed (or water) intake and how dietary sulfur might affect gut microbiota in laying hens.

Author Contributions: Conceptualization, K.-W.L. and D.-H.K.; formal analysis, S.-H.L., H.-G.L., and Y.C.; data curation, Y.-B.K.; writing—original draft preparation, Y.-B.K.; writing—review and editing, K.-W.L.; supervision, K.-W.L.; conceptualization, S.-D.L. All authors have read and agreed to the published version of the manuscript.

Funding: This work was carried out with the support of "Cooperative Research Program for Agriculture Science \& Technology Development (Project No. PJ015158)" Rural Development Administration, Korea.

Institutional Review Board Statement: All experimental protocols and the use of laying hens in the trial were approved by the Institutional Animal Care and Use of Committee of Konkuk University (KU20030), Korea.

Informed Consent Statement: Not applicable.

Data Availability Statement: Not applicable.

Conflicts of Interest: The authors declare no conflict of interest. 


\section{References}

1. Fisher-Wellman, K.; Bloomer, R.J. Acute exercise and oxidative stress: A 30 year history. Dyn. Med. 2009, 8, 1-25. [CrossRef] [PubMed]

2. Estévez, M. Oxidative damage to poultry: From farm to fork. Poult. Sci. 2015, 94, 1368-1378. [CrossRef] [PubMed]

3. Nimalaratne, C.; Wu, J. Hen egg as an antioxidant food commodity: A review. Nutrients 2015, 7, 8274-8293. [CrossRef] [PubMed]

4. Al-Harthi, M.A. The effect of natural and synthetic antioxidants on performance, egg quality and blood constituents of laying hens grown under high ambient temperature. Ital. J. Anim. Sci. 2014, 13, 444-449. [CrossRef]

5. Sasse, A.; Colindres, P.; Brewer, M.S. Effect of natural and synthetic antioxidants on the oxidative stability of cooked, frozen pork patties. J. Food Sci. 2009, 74, S30-S35. [CrossRef]

6. Edrees, G.M.; Serag, H.M.; EL-Gogary, M.R.; Alsharif, A.A. Effect of natural antioxidants supplementation as feed ingredients in laying hen diet. J. Anim. Poult. Prod. 2017, 8, 399-402. [CrossRef]

7. Radwan Nadia, L.; Hassan, R.A.; Qota, E.M.; Fayek, H.M. Effect of natural antioxidant on oxidative stability of eggs and productive and reproductive performance of laying hens. Int. J. Poult. Sci. 2008, 7, 134-150. [CrossRef]

8. Luna, A.; Lema-Alba, R.C.; Dambolena, J.S.; Zygadlo, J.A.; Labaque, M.C.; Marin, R.H. Thymol as natural antioxidant additive for poultry feed: Oxidative stability improvement. Poult. Sci. 2017, 96, 3214-3220. [CrossRef]

9. Nakhostin-Roohi, B.; Barmaki, S.; Khoshkhahesh, F.; Bohlooli, S. Effect of chronic supplementation with methylsulfonylmethane on oxidative stress following acute exercise in untrained healthy men. J. Pharm. Pharmacol. 2011, 63, 1290-1294. [CrossRef] [PubMed]

10. Butawan, M.; Benjamin, R.L.; Bloomer, R.J. Methylsulfonylmethane: Applications and safety of a novel dietary supplement. Nutrients 2017, 9, 290. [CrossRef] [PubMed]

11. Jiao, Y.; Park, J.H.; Kim, Y.M.; Kim, I.H. Effects of dietary methyl sulfonyl methane (MSM) supplementation on growth performance, nutrient digestibility, meat quality, excreta microbiota, excreta gas emission, and blood profiles in broilers. Poult. Sci. 2017, 96, 2168-2175. [CrossRef] [PubMed]

12. Wong, T.; Bloomer, R.J.; Benjamin, R.L.; Buddington, R.K. Small intestinal absorption of methylsulfonylmethane (MSM) and accumulation of the sulfur moiety in selected tissues of mice. Nutrients 2018, 10, 19. [CrossRef]

13. Hasegawa, T.; Ueno, S.; Kumamoto, S.; Yoshikai, Y. Suppressive effect of methylsulfonylmethane (MSM) on type II collageninduced arthritis in DBA/1J mice. Jpn. Pharmacol. Ther. 2004, 32, 421-427.

14. Yan, H.L.; Cao, S.C.; Hu, Y.D.; Zhang, H.F.; Liu, J.B. Effects of methylsulfonylmethane on growth performance, immunity, antioxidant capacity, and meat quality in Pekin ducks. Poult. Sci. 2020, 99, 1069-1074. [CrossRef]

15. Lim, C.I.; Choe, H.S.; Kang, C.; Lee, B.K.; Ryu, K.S. Effects of dietary organic sulfur on performance, egg quality and cell-mediated immune response of laying hens. Korean J. Poult. Sci. 2018, 45, 97-107. (In Korean) [CrossRef]

16. Madhaven, B.N.; Andersen, F.A. Final report on the safety assessment of sodium sulfate. Int. J. Toxicol. $2000,19,77-87$.

17. Ross, E.; Harms, R.H. The response of chicks to sodium sulfate supplementation of a corn-soy diet. Poult. Sci. 1970, 19, 1605-1610. [CrossRef]

18. Reid, B.L.; Weber, C.W. Lack of sulfur amino acid sparing effect with ammonium sulfate and sodium sulfate in laying hen diets. Poult. Sci. 1974, 53, 964-969. [CrossRef]

19. Kerr, B.J.; Weber, T.E.; Ziemer, C.J.; Spence, C.; Cotta, M.A.; Whitehead, T.R. Effect of dietary inorganic sulfur level on growth performance, fecal composition, and measures of inflammation and sulfate-reducing bacteria in the intestine of growing pigs. J. Anim. Sci. 2011, 89, 426-437. [CrossRef] [PubMed]

20. Park, S.O.; Park, B.S. Dietary sulphur as alternative antibacterial supplements for broiler chickens. Eur. Poult. Sci. 2017, 81, 191. [CrossRef]

21. Bohlooli, S.; Mohammadi, S.; Amirshahrokhi, K.; Mirzanejad-Asl, H.; Yosefi, M.; Mohammadi-Nei, A.; Chinifroush, M.M. Effect of methylsulfonylmethane pretreatment on acetaminophen induced hepatotoxicity in rats. Iran. J. Basic Med. Sci. 2013, 16, 896-900. [CrossRef] [PubMed]

22. Kamel, R.; El Morsy, E.M. Hepatoprotective effect of methylsulfonylmethane against carbon tetrachloride-induced acute liver injury in rats. Arch. Pharm. Res. 2013, 36, 1140-1148. [CrossRef] [PubMed]

23. Battin, E.E.; Brumaghim, J.L. Antioxidant activity of sulfur and selenium: A review of reactive oxygen species scavenging, glutathione peroxidase, and metal-binding antioxidant mechanisms. Cell Biochem. Biophys. 2009, 55, 1-23. [CrossRef] [PubMed]

24. Withee, E.D.; Tippens, K.M.; Dehen, R.; Tibbitts, D.; Hanes, D.; Zwickey, H. Effects of Methylsulfonylmethane (MSM) on exerciseinduced oxidative stress, muscle damage, and pain following a half-marathon: A double-blind, randomized, placebo-controlled trial. J. Int. Soc. Sports Nutr. 2017, 14, 1-11. [CrossRef]

25. Saedi, S.; Shokri, M.; Rhim, J.W. Antimicrobial activity of sulfur nanoparticles: Effect of preparation methods. Arab. J. Chem. 2020, 13, 6580-6588. [CrossRef]

26. Park, S.-W.; Lee, W. Development of a validated determination of methylsulfonylmethane in dietary supplement by gas chromatography. Korean Soc. Biotechnol. Bioeng. J. 2015, 30, 141-147. (In Korean) [CrossRef]

27. Wang, W.W.; Wang, J.; Zhang, H.J.; Wu, S.G.; Qi, G.H. Transcriptome analysis reveals mechanism underlying the differential intestinal functionality of laying hens in the late phase and peak phase of production. BMC Genom. 2019, 20, 970. [CrossRef]

28. Korean Feeding Standards for Poultry. National Institute of Animal Science; RDA: Suwon, Korea, 2012. (In Korean) 
29. Lee, S.H.; Kim, Y.B.; Kim, D.-H.; Lee, D.-W.; Lee, H.-G.; Jha, R.; Lee, K.-W. Dietary soluble flaxseed oils as a source of omega3 polyunsaturated fatty acids for laying hens. Poult. Sci. 2021, 100, 101276. [CrossRef]

30. Kim, Y.B.; Kim, D.H.; Jeong, S.B.; Lee, J.W.; Kim, T.H.; Lee, H.G.; Lee, K.W. Black soldier fly larvae oil as an alternative fat source in broiler nutrition. Poult. Sci. 2020, 99, 3133-3143. [CrossRef]

31. Bradford, M.M. A rapid and sensitive method for the quantitation of microgram quantities of protein utilizing the principle of protein-dye binding. Anal. Biochem. 1976, 72, 248-254. [CrossRef]

32. Duncan, D.B. Multiple range and multiple F tests. Biometrics 1955, 11, 1-42. [CrossRef]

33. Krista, L.M.; Carlson, C.W.; Olson, O.E. Some effects of saline waters on chicks, laying hens, poults, and ducklings. Poult. Sci. 1961, 40, 938-944. [CrossRef]

34. Adams, A.W.; Cunningham, F.E.; Munger, L.L. Some effects on layers of sodium sulfate and magnesium sulfate in their drinking water. Poult. Sci. 1975, 54, 707-714. [CrossRef]

35. Nockels, C.F. The influence of feeding ascorbic acid and sulfate on egg production and on cholesterol content of certain tissues of the hen. Poult. Sci. 1973, 52, 373-378. [CrossRef]

36. Ross, E.; Damron, B.L.; Harms, R.H. The requirement for inorganic sulfate in the diet of chicks for optimum growth and feed efficiency. Poult. Sci. 1972, 51, 1606-1612. [CrossRef]

37. Food and Drug Administration. Frequency of Use of Cosmetic Ingredients; FDA: Aurora, IL, USA, 2016.

38. Ahmad, T.; Mushtaq, T.; Mahr-Un-Nisa; Sarwar, M.; Hooge, D.M.; Mirza, M.A. Effect of different non-chloride sodium sources on the performance of heat-stressed broiler chickens. Br. Poult. Sci. 2006, 47, 249-256. [CrossRef]

39. Park, S.O.; Shin, J.H.; Choi, W.K.; Park, B.S. Effect of feeding dietary legislation sulfur as an antibiotic replacement in broiler chickens. Ann. Anim. Resour. Sci. 2010, 21, 32-39.

40. Honda, B.T.B.; Calefi, A.S.; Costola-De-Souza, C.; Quinteiro-Filho, W.M.; Da Silva Fonseca, J.G.; De Paula, V.F.; Palermo-Neto, J. Effects of heat stress on peripheral $\mathrm{T}$ and B lymphocyte profiles and IgG and IgM serum levels in broiler chickens vaccinated for Newcastle disease virus. Poult. Sci. 2015, 94, 2375-2381. [CrossRef]

41. Downing, J.A.; Bryden, W.L. Determination of corticosterone concentrations in egg albumen: A non-invasive indicator of stress in laying hens. Physiol. Behav. 2008, 95, 381-387. [CrossRef] [PubMed]

42. Hayward, L.S.; Wingfield, J.C. Maternal corticosterone is transferred to avian yolk and may alter offspring growth and adult phenotype. Gen. Comp. Endocrinol. 2004, 135, 365-371. [CrossRef] [PubMed]

43. Poole, T.L.; Benjamin, R.; Genovese, K.J.; Nisbet, D.J. Methylsulfonylmethane exhibits bacteriostatic inhibition of Escherichia coli, and Salmonella enterica Kinshasa, in vitro. J. Appl. Microbiol. 2019, 127, 1677-1685. [CrossRef]

44. Scott, B.R.; Yang, X.; Geornaras, I.; Delmore, R.J.; Woerner, D.R.; Reagan, J.O.; Morgan, J.B.; Belk, K.E. Antimicrobial efficacy of a sulfuric acid and sodium sulfate blend, peroxyacetic acid, and cetylpyridinium chloride against Salmonella on inoculated chicken wings. J. Food Prot. 2015, 78, 1967-1972. [CrossRef]

45. Caspary, W.F. Physiology and pathophysiology of intestinal absorption. Am. J. Clin. Nutr. 1992, 55, 299S-308S. [CrossRef] [PubMed]

46. Wang, J.X.; Peng, K.M. Developmental morphology of the small intestine of African ostrich chicks. Poult. Sci. 2008, 87, 2629-2635 [CrossRef] [PubMed]

47. Pohanka, M.; Martinkova, P.; Brtnicky, M.; Kynicky, J. Changes in the oxidative stress/anti-oxidant system after exposure to sulfur mustard and antioxidant strategies in the therapy, a review. Toxicol. Mech. Methods 2017, 27, 408-416. [CrossRef] [PubMed]

48. Freeman, B.A.; Crapo, J.D. Hyperoxia increases oxygen radical production in rat lungs and lung mitochondria. J. Biol. Chem. 1981, 256, 10986-10992. [CrossRef]

49. Nakhostin-Roohi, B.; Niknam, Z.; Vaezi, N.; Mohammadi, S.; Bohlooli, S. Effect of single dose administration of methylsulfonylmethane on oxidative stress following acute exhaustive exercise. Iran. J. Pharm. Res. 2013, 12, 845-853.

50. Lee, J.I.; Min, H.K.; Lee, J.W.; Jeong, J.D.; Ha, Y.J.; Kwack, S.C.; Park, J.S. Changes in the quality of loin from pigs supplemented with dietary methyl sulfonyl methane during cold storage. Korean J. Food Sci. Anim. Resour. 2009, 29, 229-237. [CrossRef]

51. Shin, J.-S.; Kim, M.-A.; Lee, S.-H. Comparison of physiological changes in broiler chicken fed with dietary processed sulfur. Korean Soc. Food Preserv. 2013, 20, 278-283. (In Korean) [CrossRef]

52. Abdul Rasheed, M.S.; Oelschlager, M.L.; Smith, B.N.; Bauer, L.L.; Whelan, R.A.; Dilger, R.N. Dietary methylsulfonylmethane supplementation and oxidative stress in broiler chickens. Poult. Sci. 2020, 99, 914-925. [CrossRef] [PubMed]

53. Kusano, C.; Ferrari, B. Total antioxidant capacity: A biomarker in biomedical and nutritional studies. J. Cell Mol. Biol. 2008, 7, 1-15.

54. Ighodaro, O.M.; Akinloye, O.A. First line defence antioxidants-superoxide dismutase (SOD), catalase (CAT) and glutathione peroxidase (GPX): Their fundamental role in the entire antioxidant defence grid. Alexandria J. Med. 2018, 54, 287-293. [CrossRef]

55. Hwang, J.W.; Cheong, S.H.; Kim, Y.S.; Lee, J.W.; You, B.I.; Moon, S.H.; Jeon, B.T.; Park, P.J. Effects of dietary supplementation of oriental herbal medicine residue and methyl sulfonyl methane on the growth performance and meat quality of ducks. Anim. Prod. Sci. 2017, 57, 948-957. [CrossRef]

56. Marãn, G.; Mũoz-Escassi, B.; Manley, W.; García, C.; Cayado, P.; De La Muela, M.S.; Olábarri, B.; Len, R.; Vara, E. The effect of methyl sulphonyl methane supplementation on biomarkers of oxidative stress in sport horses following jumping exercise. Acta Vet. Scand. 2008, 50, 45. [CrossRef] [PubMed] 